\title{
Effect of advance drainage on tunnel face stability using Limit Analysis and numerical simulations
}

\author{
Congke Yi, Salvador Senent, Rafael Jimenez* \\ Universidad Politécnica de Madrid, Spain
}

Keywords:

Kinematical approach

Pore water pressure

Advance borehole drainage

Critical pressure

Numerical validation

\begin{abstract}
A B S T R A C T
Positive pore water pressures ahead of tunnels constructed under the water table influence the stability of the tunnel face, and they may considerably affect the safety of tunneling operations. Advance drainage is often necessary, since traditional support measures may be insufficient to provide the required face support pressures. This work presents an Upper Bound Solution, in the framework of Limit Analysis, to assess the stability of a tunnel face considering the influence of advance drainage boreholes in two different arrangements, upper and lower. Results of the proposed Limit Analysis approach are compared with the results of a numerical model in FLAC $^{3 \mathrm{D}}$ for a tunnel with a $D=10 \mathrm{~m}$ diameter, demonstrating that the critical pressures and failure geometries computed with the analytical solution correctly reproduce the FLAC ${ }^{3 \mathrm{D}}$ results when the height of the water table above the tunnel crown is lower than 5 tunnel diameters. Similarly, our results are compared with the results of a similar face stability analysis conducted with a Limit Equilibrium mechanism, suggesting that the Limit Analysis approach gives lower collapse pressure values, with relative differences of up to $30 \%$ (mainly depending on the water level and on the drainage configuration), and with results that generally agree better with the numerical simulation results. Finally, the influence of the borehole layout at the tunnel face is analyzed considering different water table positions. Results confirm that the water level has a significant influence on face stability (both on critical pressure values and on failure geometries), that the advance drainage considered significantly reduces the support pressure required for stability, and that the advance drainage configuration can also affect the shape of the critical failure mechanism.
\end{abstract}

\section{Introduction}

Construction accidents in tunnelling are frequently related to water problems, like high water inflows or induced tunnel face collapses (Anagnostou, 2014). The required tunnel face support pressure is an important parameter to monitor during tunnel construction (e.g., in an EPB or slurry shield; see e.g. Mair, 2008) and positive pore water pressures due to seepage at the tunnel face decrease the stability of tunnel faces (Lü et al., 2018). The face support pressure required to stabilize the face of a tunnel excavated under the water table cannot often be provided with traditional support measures or with mechanized tunnel excavation, so that alternative treatments, such as advance drainage, are required (Anagnostou, 2014).

Laboratory tests have been conducted to analyze the stability of the tunnel face under seepage conditions (e.g., Lee et al, 2003). More recently, Lü et al. (2018) have studied the influence that the cover to diameter ratio $(C / D)$ and the water level have on the collapse pressure and on the failure geometry. However, these previous works did not consider advance drainage. Similarly, several works have employed numerical models to study the effect of the pore pressures on the stability of the tunnel face (e.g., Li et al., 2011) but most of them did not consider advance drainage. Hong et al. (2007) studied the effects of horizontal pre-drainage on the pore water pressures and on the flow rates in subsea tunnels. They demonstrate the relevance of drainage, giving suggestions on the length of drainage to be used under different ground permeabilities.

Analytical solutions have been proposed to investigate the stability of a tunnel face under seepage conditions, such as, for example, the classical Limit Equilibrium mechanism formed by a wedge and an upper prism and based on the silo-theory (Anagnostou and Kovári, 1994, 1996). This solution has been employed by Zingg (2016) to study the effect of advance drainage on tunnel face stability, in a thorough analysis of the effectiveness of drainage boreholes and of other designs (pilot tunnels, twin tunnels, drainage curtains, etc.) to improve the stability of the face in homogenous and non-homogenous permeability fields (see also Zingg and Anagnostou, 2016, 2018).

\footnotetext{
* Corresponding author at: ETSI Caminos, C. y P., C/ Profesor Aranguren s/n, 28040 Madrid, Spain.

E-mail address: rafael.jimenez@upm.es (R. Jimenez).
} 


\begin{tabular}{|c|c|c|c|}
\hline \multicolumn{2}{|c|}{ Notation } & $\omega$ & angular velocity of the collapse mechanism \\
\hline$c$ & soil cohesion & $\gamma_{\text {sat }}$ & \\
\hline & & $\gamma$ & submerged unit weight \\
\hline$\varphi$ & friction angle & $\sigma_{T}$ & support pressure \\
\hline$D$ & tunnel diameter & $O$ & center of rotation of the mechanism in the vertical plane of \\
\hline C & overburden & & symmetry of the tunnel \\
\hline $\begin{array}{l}H_{w} \\
h_{0}\end{array}$ & $\begin{array}{l}\text { water elevation from the tunnel crown } \\
\text { initial hydraulic head at the tunnel axis }\end{array}$ & $R_{E}, \beta_{E}$ & $\begin{array}{l}\text { polar coordinates of the center of rotation of the me- } \\
\text { chanism }\end{array}$ \\
\hline$h$ & hydraulic head & $R_{i, j}, \beta_{i, j}$ & polar coordinates of the barycenter of triangular facet \\
\hline$n$ & number of drainage boreholes & $R_{i, j}^{\prime}, \beta_{i, j}^{\prime}$ & polar coordinates of the barycenter of triangular facet $F_{i, j}^{\prime}$ \\
\hline$L$ & drainage boreholes length & $R_{i, 0}, \beta_{i, 0}$ & polar coordinates of points on the tunnel face \\
\hline$d$ & drainage boreholes diameter & $\begin{array}{l}V_{i, j}, P_{i, 0} \\
V_{i, j}\end{array}$ & element volume corresponding to facet \\
\hline y & distance from the tunnel face & $V_{i, j}^{\prime}$ & element volume corresponding to facet $F_{i, j}^{\prime}$ \\
\hline$W_{\gamma}$ & soil weight & $S_{i, 0}^{l, j}$ & area of discretized element on the tunnel face \\
\hline$W_{\gamma}^{g}$ & work rate of soil weight & $S_{i, j}$ & area of facet \\
\hline$W_{T}$ & support force applied on the tunnel face & $S_{i, j}^{\prime}$ & area of facet $F_{i j}^{\prime}$ \\
\hline$W_{T}^{g}$ & work rate of support force applied on the tunnel face & $\begin{array}{l}D_{i, j} \\
\varepsilon_{i i}^{g}\end{array}$ & volumetric strain \\
\hline$W_{s}$ & ground surcharge & & $\begin{array}{l}\text { volumetric strain } \\
\text { pore water pressure }\end{array}$ \\
\hline$W_{s}^{g}$ & work rate of ground surcharge & & pore water pressure \\
\hline$W_{u}$ & resultant force due to pore water pressures & $u_{i, 0}$ & $\begin{array}{l}\text { pore water pressure of the barycenter of the discretized } \\
\text { element } S_{i, 0}\end{array}$ \\
\hline $\begin{array}{l}W_{u}^{g} \\
W_{D}^{g}\end{array}$ & $\begin{array}{l}\text { work rate of pore water pressures } \\
\text { work rate of internal energy dissipation }\end{array}$ & $u_{i, j}$ & pore water pressure in the location of the barycenter of \\
\hline $\begin{array}{l}w \\
\vec{v}\end{array}$ & $\begin{array}{l}\text { initial slope (or critical angle) of the failure surface } \\
\text { velocity vector in the kinematically admissible velocity } \\
\text { field }\end{array}$ & $u_{i, j}^{\prime}$ & $\begin{array}{l}\text { triangular facet } \\
\text { pore water pressure in the location of the barycenter of } \\
\text { triangular facet } F_{i, j}^{\prime}\end{array}$ \\
\hline
\end{tabular}

Seepage forces have also been incorporated into existing upper bound Limit Analysis mechanisms to study the stability of the tunnel face: for instance, Lee et al. (2001) employed the mechanism by Leca and Dormieux (1990), whereas Pan and Dias (2016) employed the rotational mechanism by Mollon et al. (2011a). Pan and Dias further analyzed the influence of aspects such as the anisotropy of permeability fields (Pan and Dias, 2016), or even the behavior of tunnels constructed, under the water table, in weak rock masses that follow the Hoek-Brown criterion (Pan and Dias, 2018). However, a Limit Analysis upper bound solution has never been employed to compute the stability of a tunnel face considering the influence of advance drainage.

Since Limit Analysis has become a widely used tool to assess the stability of a tunnel face in the last few years, a study to analyze the influence of advance drainage using Limit Analysis is considered as a useful contribution to the literature on the field. This paper presents such a study, and it analyzes the face stability of a circular tunnel under the water table, considering advance drainage and using the kinematical approach of Limit Analysis. The 3D rotational failure mechanism developed by Mollon et al. (2011a) is extended to investigate the stabilizing effect of advance drainage boreholes employed to reduce the pore water pressure in the ground ahead of the tunnel face. An extensive comparison with numerical simulations is carried out to validate the results of the analytical approach, and to study the effect of drainage on the stability of the tunnel face. Finally, the results of the proposed Limit Analysis mechanism are compared to those computed with the Limit Equilibrium solution developed by Anagnostou and Kovári (1994, 1996), using the methodology proposed by Zingg (2016).

\section{Limit Analysis mechanism considering pore water pressure and the effect of advance drainage}

\subsection{Model description}

Fig. 1(a) shows a longitudinal section of the problem analyzed herein: a circular tunnel excavated under the water table and with advance drainage boreholes. The tunnel has a diameter of $D=10 \mathrm{~m}$ and an overburden, $C$, of between 20 and $50 \mathrm{~m} . H_{w}$ represents the water elevation from the tunnel crown (it also ranges between 20 and $50 \mathrm{~m}$ ) and $h_{0}$ is the initial hydraulic head at the tunnel axis. As shown in Fig. 1(b), we consider two horizontal drainage boreholes of diameter
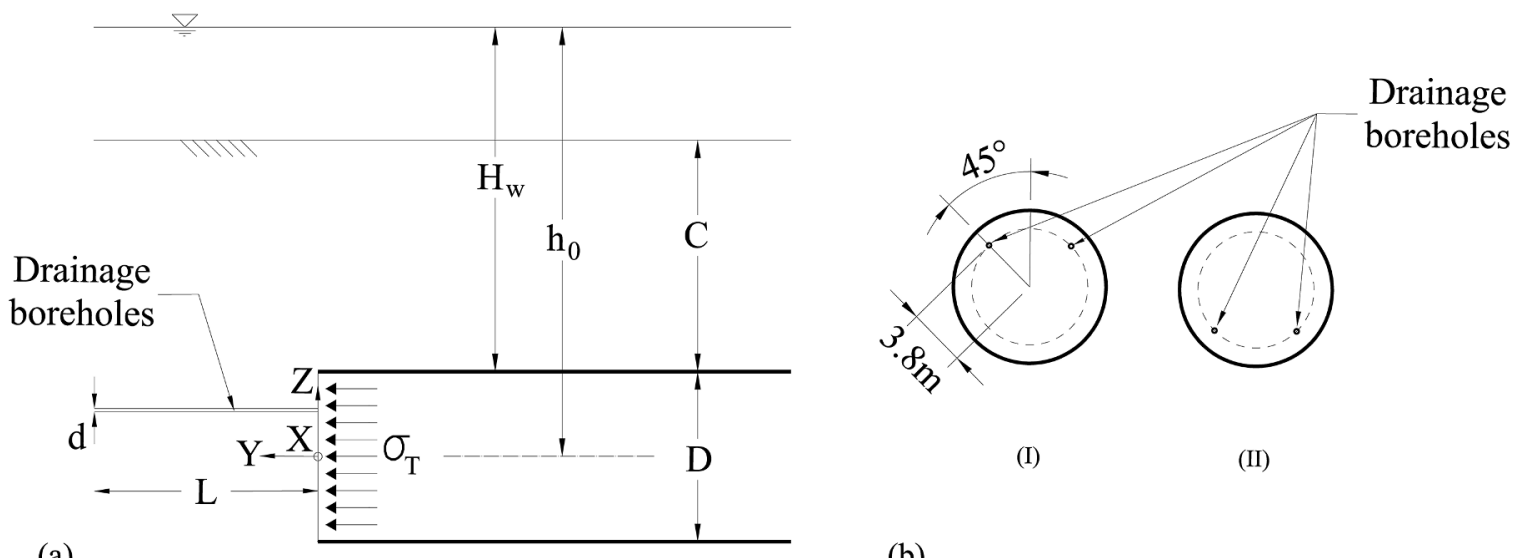

(a)

Fig. 1. Outline of the analyzed problem: (a) in the vertical plane of symmetry of the tunnel; (b) in the tunnel face cross-section. (Boreholes layout: (I) "upper" drainage; (II) "lower" drainage.) 
$d=0.2 \mathrm{~m}$ and length $L=30 \mathrm{~m}$ distributed symmetrically with an angle of $45^{\circ}$ from the vertical and with a distance to the center of the tunnel face $r=3.8 \mathrm{~m}$, in two different locations: (I) "upper" drainage; and (II) "lower" drainage.

\subsection{Limit Analysis mechanism}

We employ the Limit Analysis mechanism proposed by Mollon et al. (2011a), considering the effect of the pore pressure distribution as proposed by Pan and Dias (2016). The collapse mechanism is formed by a unique non-deformable block that rotates around a horizontal line perpendicular to the vertical plane of symmetry of the tunnel (see Fig. 2). The mechanism is bounded, in this plane of symmetry, by two log-spirals emerging from the crown and invert of the tunnel face that have the same center (Point $\mathrm{O}$ in Fig. 2(b)). To generate the 3D failure surface that originates from the tunnel face and fulfills the associated flow rule, as required by the Limit Analysis theorems, a "point by point" spatial discretization technique is used, as explained in Mollon et al. (2011a). This technique first discretizes the tunnel perimeter in a set of points $A_{i}$ and defines a set of radial planes $\Pi_{j}$, perpendicular to the vertical plane of symmetry, that pass through the center of rotation of the mechanism (see Fig. 2). Then, if two points $P_{i, j}$ and $P_{i+1, j}$ in plane $\Pi_{j}$ are known, a third point $P_{i, j+1}$ in plane $\Pi_{j+1}$ can be obtained, so that the triangular facet (defined by $P_{i, j}, P_{i+1, j}$ and $P_{i, j+1}$ ) fulfills the associated flow rule hypothesis of Limit Analysis (see Fig. 3). Similarly, $F_{i, j}^{\prime}$ can be obtained from points $P_{i+1, j}, P_{i, j+1}$, and $P_{i+1, j+1}$ ). When the surface of the collapse mechanism is completely defined by the set of faces and $F_{i, j}{ }^{\prime}$, an upper bound of the collapse pressure can be obtained by equating (i) the total rate of work applied to the system by the external forces and (ii) the rate of energy dissipated in the system due to shear forces developed by Mohr-Coulomb soils.

In the employed mechanism, the external forces comprise the soil weight, $W_{\gamma}$; the support force applied on the tunnel face, $W_{T}$; and, if the failure mechanism outcrops at the surface, the ground surcharge, $W_{s}$; additionally, the resultant force due to the seepage and buoyancy forces, $W_{u}$, is considered. The rate of work of the soil weight $\left(W_{\gamma}^{g}\right)$, of the support force applied on the tunnel face $\left(W_{T}^{g}\right)$, and of the internal energy dissipated along the failure surface $\left(W_{D}^{g}\right)$ are formulated concisely

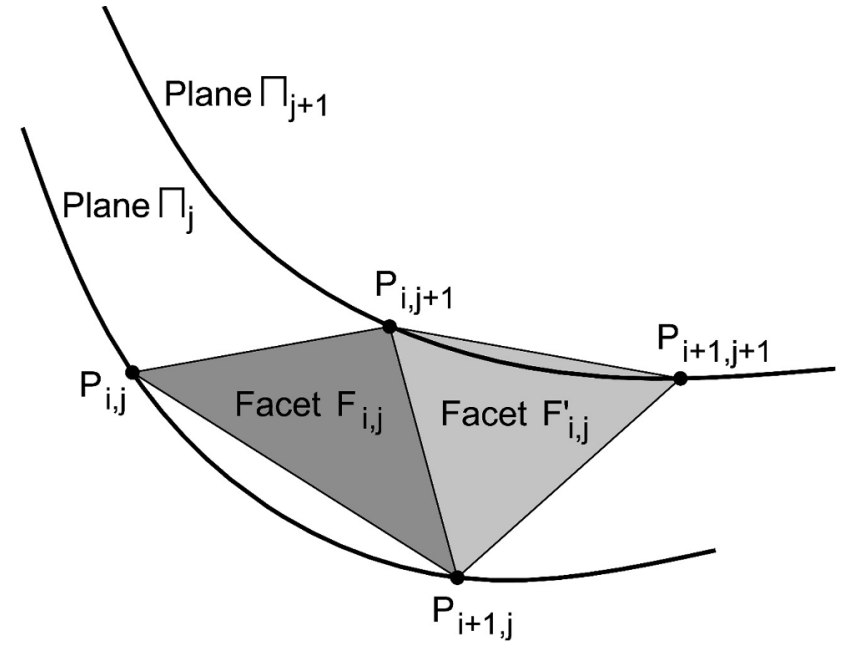

Fig. 3. Point-by-point generation of the external surface of the mechanism (simplified from Mollon et al. (2011a), Fig. 4).

in Eqs. (1)-(3) respectively (more details can be found in Mollon et al., 2011a, and in Pan and Dias, 2016).

$W_{\gamma}^{g}=\iiint_{V} \vec{\gamma} \cdot \vec{v} \cdot d V=\omega \cdot \gamma_{s a t} \cdot \sum_{i} \sum_{j}\left(R_{i, j} \cdot V_{i, j} \cdot \sin \beta_{i, j}+R_{i, j}^{\prime} \cdot V_{i, j}^{\prime} \cdot \sin \beta_{i, j}^{\prime}\right)$

$W_{T}^{g}=\iint_{S} \vec{\sigma}_{t} \cdot \vec{v} \cdot d S=-\omega \cdot \sigma_{t} \cdot \sum_{i}\left(S_{i, 0} \cdot R_{i, 0} \cdot \cos \beta_{i, 0}\right)$

$W_{D}^{g}=\iint_{S} c \cdot v \cdot \cos \varphi \cdot d S=\omega \cdot c \cdot \cos \varphi \cdot \sum_{i} \sum_{i}\left(R_{i, j} \cdot S_{i, j}+R_{i, j}^{\prime} \cdot S_{i, j}^{\prime}\right)$

where $R_{i, j}, V_{i, j}, \beta_{i, j}, S_{i, j}, R_{i, j}^{\prime}, V_{i, j}^{\prime}, \beta_{i, j}^{\prime}, S_{i, j}^{\prime}, R_{i, 0}, \beta_{i, 0}, S_{i, 0}$ are geometrical terms defined in Mollon et al. (2011a). In addition, note that the saturated unit weight $\gamma_{\text {sat }}$ is used in this paper as the collapse mechanisms considered always develop under the water table. Furthermore, since they never outcrop at the surface, the rate of work due to the ground surcharge is always null in this work.
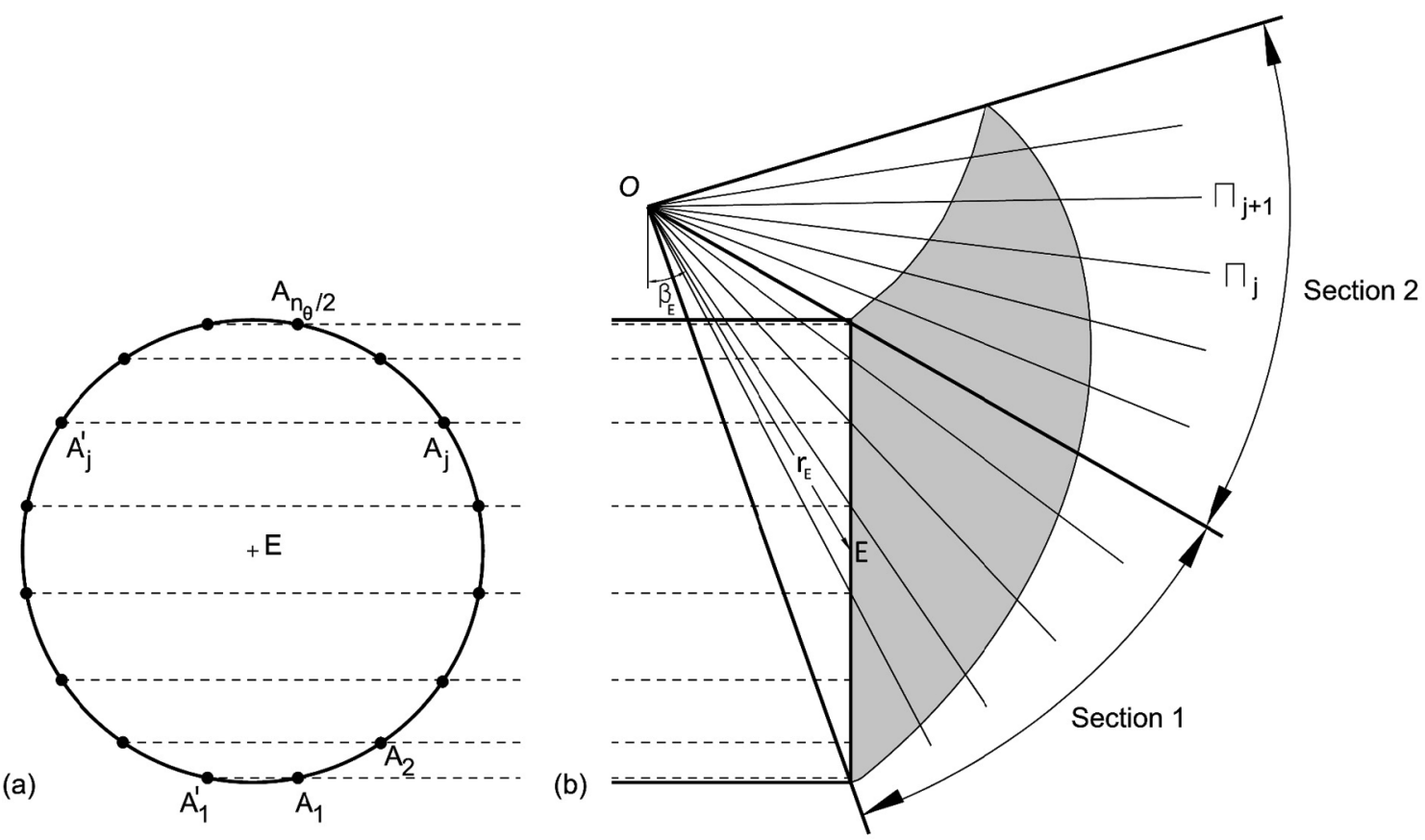

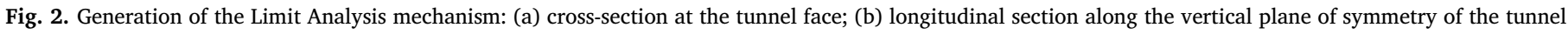
(simplified from Mollon et al. (2011a), Fig. 3). 


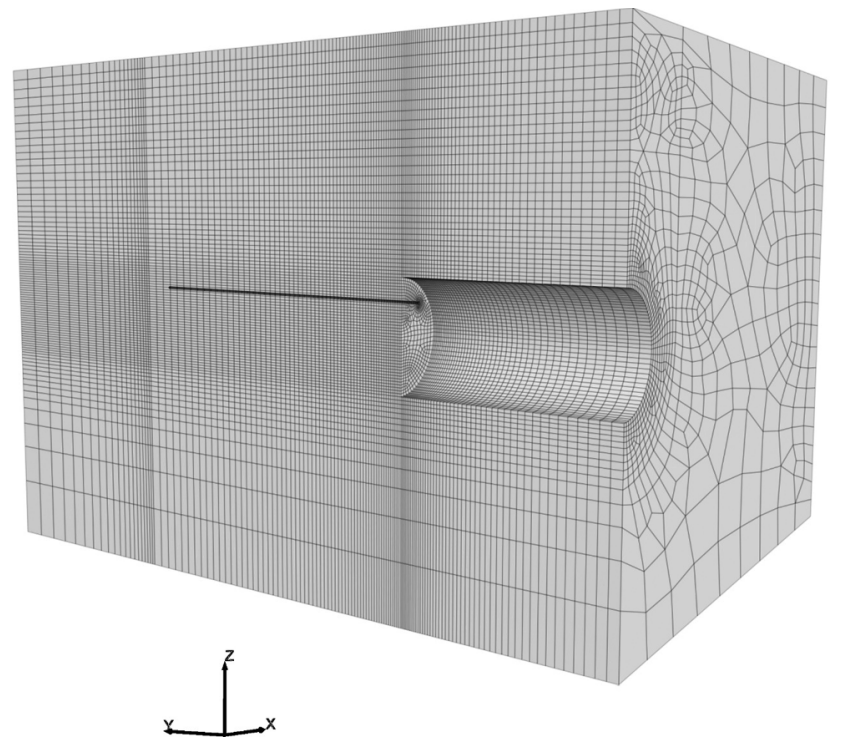

Fig. 4. Numerical model with advance drainage boreholes employed to calculate the pore water pressure distribution and the collapse pressure.

According to Viratjandr and Michalowski (2006), the rate of work due to the seepage and buoyancy forces $\left(W_{u}^{g}\right)$ can be computed using the pore water pressures; following Pan and Dias (2016), we have:

$$
\begin{aligned}
W_{u}^{g}= & -\iiint_{V} u \cdot \varepsilon_{i i}^{g} \cdot d V-\iint_{S} u \cdot n_{i} \cdot v_{i} \cdot d S \\
= & \omega \cdot \sum_{i}\left(u_{i, 0} \cdot S_{i, 0} \cdot R_{i, 0} \cdot \cos \beta_{i, 0}\right)+\omega \cdot \sin \varphi \cdot \\
& \sum_{i} \sum_{j}\left(u_{i, j} \cdot R_{i, j} \cdot S_{i, j}+u_{i, j}^{\prime} \cdot R_{i, j}^{\prime} \cdot S_{i, j}^{\prime}\right)+\omega \cdot \sum_{i}\left(u_{i} \cdot S_{i} \cdot R_{i} \cdot \sin \beta_{i}\right)
\end{aligned}
$$

where the volumetric strain $\varepsilon_{i i}^{g}$ is equal to zero because of the rigid block assumption. Additionally, the pore pressure at the tunnel face $\left(u_{i, 0}\right)$ is assumed to be atmospheric, so that the first term in the right side of Eq. (4) is equal to zero; and $u_{i}$-which represents the pore water pressure at outcropped elements- is also zero because the mechanisms considered herein never outcrop at the surface. Then, the rate of work due to pore water pressures becomes (Pan and Dias, 2016):

$W_{u}^{g}=-\iint_{S} u \cdot n_{i} \cdot v_{i} \cdot d S=\omega \cdot \sin \varphi \cdot \sum_{i} \sum_{j}\left(u_{i, j} \cdot R_{i, j} \cdot S_{i, j}+u_{i, j}^{\prime} \cdot R_{i, j}^{\prime} \cdot S_{i, j}^{\prime}\right)$

where $u_{i, j}$ and $u_{i, j}^{\prime}$ represent the pore pressures in the triangular facets that form the external surface of the mechanism. In this work, they are obtained interpolating in the pore water pressure distributions computed with the numerical model described in the next section.

After applying the work equation, the support pressure can be expressed as (Pan and Dias, 2016):

$$
\begin{aligned}
\sigma_{T}= & \frac{\gamma_{s a t} \cdot \sum_{i} \sum_{j}\left(R_{i, j} \cdot V_{i, j} \cdot \sin \beta_{i, j}+R_{i, j}^{\prime} \cdot V_{i, j}^{\prime} \cdot \sin \beta_{i, j}^{\prime}\right)}{\sum_{i}\left(S_{i, 0} \cdot R_{i, 0} \cdot \cos \beta_{i, 0}\right)}-\frac{c \cdot \cos \varphi \cdot \sum_{i} \sum_{i}\left(R_{i, j} \cdot S_{i, j}+R_{i, j}^{\prime} \cdot S_{i, j}^{\prime}\right)}{\sum_{i}\left(S_{i, 0} \cdot R_{i, 0} \cdot \cos \beta_{i, 0}\right)} \\
& +\frac{\sin \varphi \cdot \sum_{i} \sum_{j}\left(u_{i, j} \cdot R_{i, j} \cdot S_{i, j}+u_{i, j}^{\prime} \cdot R_{i, j}^{\prime} \cdot S_{i, j}^{\prime}\right)}{\sum_{i}\left(S_{i, 0} \cdot R_{i, 0} \cdot \cos \beta_{i, 0}\right)}
\end{aligned}
$$

The optimal value of $\sigma_{T}$ can be obtained by maximizing Eq. (6) with respect to the two coordinates that define the position of the center of rotation of the mechanism in the vertical plane of symmetry $\left(\beta_{E}\right.$ and $R_{E}$; see Fig. 2(b)). The obtained value of $\sigma_{T}$ represents a lower bound of the support pressure required to stabilize the face, considering the influence of water seepage.

\subsection{Numerical computation of pore water pressure distributions (without and with drainage)}

To obtain the pore water pressure distribution required by the Limit
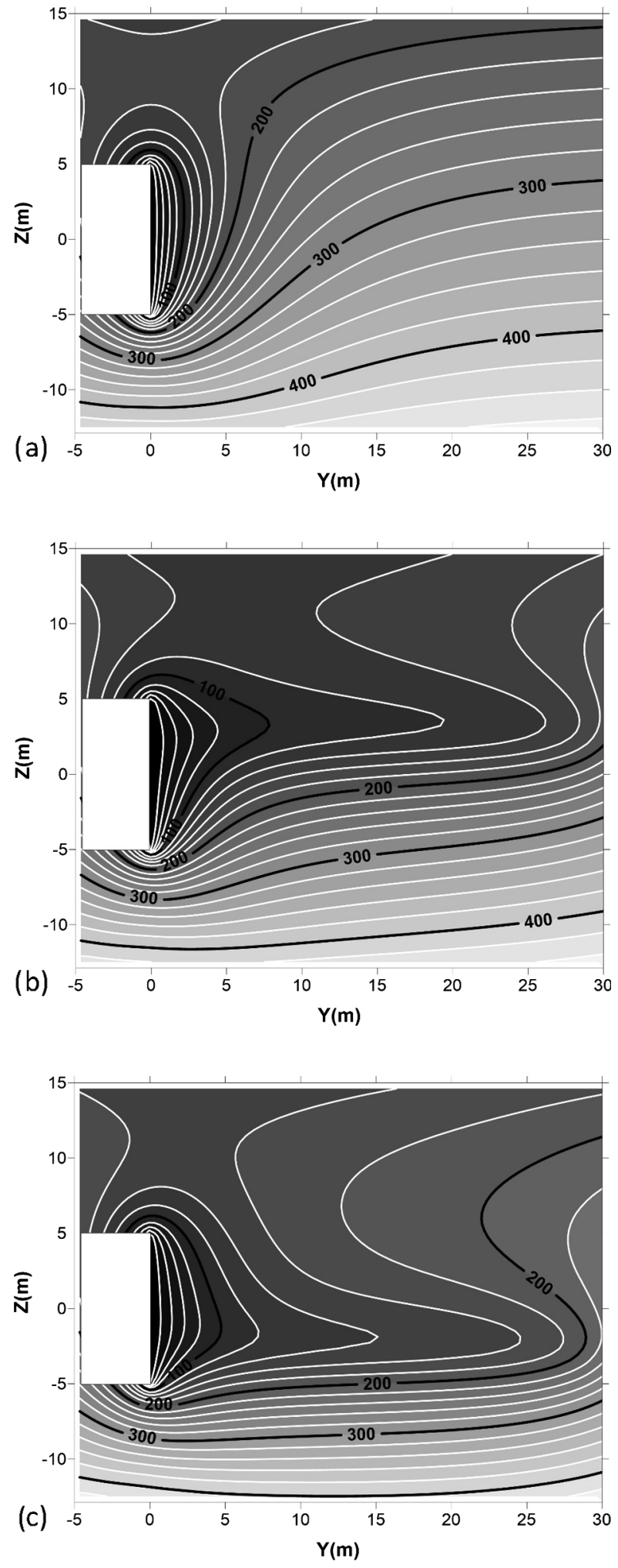

Fig. 5. Contours of the pore water pressure distribution in the numerical model for different drainage configurations: (a) without drainage; (b) "upper" drainage boreholes; (c) "lower" drainage boreholes. ( $\left.D=10 \mathrm{~m} ; C=2 D ; H_{w}=3 D\right)$. (Values shown indicate the hydraulic head in $\mathrm{kPa}$ ).

Analysis solution, we employ a numerical model built in FLAC ${ }^{3 \mathrm{D}}$ (Itasca Consulting Group, 2009). In the numerical model, shown in Fig. 4, the tunnel has a diameter of $D=10 \mathrm{~m}$ and the overburden is $C=20 \mathrm{~m}$. Taking advantage of the symmetry of the problem, and to decrease the computing times, only half of the model is considered. The dimensions 


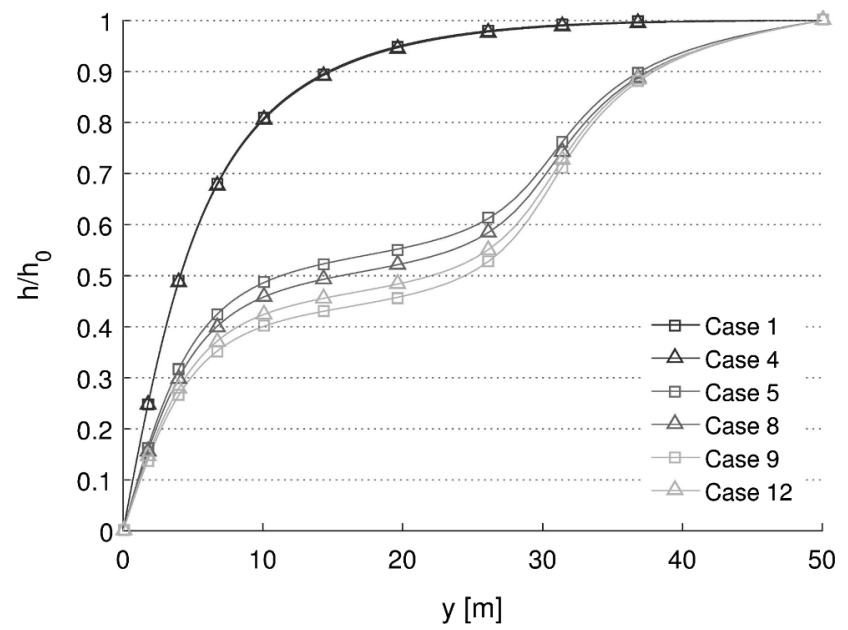

Fig. 6. Distribution of hydraulic head along the tunnel axis for several Test Cases (see Table 1 ). ( $h$ : hydraulic head; $h_{0}$ : initial hydraulic head; $y$ : distance from the tunnel face).

of the numerical model are $55 \times 70 \times 50 \mathrm{~m}^{3}$ in $x, y$ and $z$ directions, respectively. The model has 157500 zones and the mesh ahead of the tunnel face is refined for a more precise interpolation of pore water pressures in the vicinity of the collapse mechanism.

The water table is assumed to maintain a constant elevation $\left(H_{w}\right.$ in Fig. 1(a)), whose value depends on the case considered. The lower and lateral external boundaries of the numerical model, including the longitudinal plane of symmetry of the tunnel, are impermeable. The tunnel perimeter is also assumed to be impermeable, so that the tunnel face becomes the only surface into which the groundwater can flow. When the advance drainage boreholes are considered, the "null" model is applied to zones representing the location of the boreholes, and an atmospheric pressure (equal to zero) is imposed to them.

As an example of the results of the numerical model, Fig. 5 shows the distributions of pore water pressures in the vertical plane of symmetry of the tunnel, when the water table is 3 diameters above the tunnel crown $\left(H_{w}=3 D\right)$, and for the cases without drainage and with "upper" and "lower" drainage. As expected, Fig. 5 shows (i) that advance drainage reduces pore water pressures ahead of the tunnel face and (ii) that the distribution of the reduced pressures varies with the location of the boreholes.
To illustrate the effect of drainage better, Fig. 6 presents the hydraulic heads along the tunnel axis for several Test Cases listed in Table 1. (These Test Cases are later employed for the numerical validation of the mechanism). As it can be observed, advance drainage (Cases 5, 8, 9 and 12) significantly reduces the pore water pressures ahead of the tunnel face, so that such reduction extends up to the total length of the drainage boreholes $(30 \mathrm{~m})$ and even beyond. In addition, it shows that the "lower" drainage layout (Cases 9 and 12) is more effective to reduce the hydraulic head along the tunnel axis than the "upper" layout (Cases 5 and 8). And, although it is less appreciable, this difference of efficiency is reduced when the water level is raised (See Cases 5 and 9 for $H_{w} / D=2$ and Cases 8 and 12 for $H_{w} / D=5$ ). (Similar results have been obtained by Zingg (2016), although she considered higher $H_{w} / D$ ratios and, as explained later, the effectiveness of drainage to stabilize the tunnel face depends on the water level).

\section{Numerical validation}

\subsection{Test Cases}

To validate the proposed methodology, 15 Test Cases are employed (see Table 1), to compare the results of the Limit Analysis solution -in particular, the critical pressure and the collapse geometry- with the results of the numerical model in FLAC ${ }^{3 \mathrm{D}}$.

A tunnel with a diameter of $10 \mathrm{~m}$ in a purely frictional material $\left(\varphi=35^{\circ}\right)$ with a saturated unit weight of $15.6 \mathrm{kN} / \mathrm{m}^{3}$ is assumed, considering different elevations of the water table $\left(H_{w} / D=2-5\right)$ and different drainage configurations (without drainage, and with "upper" and "lower" drainage). In general, an overburden of two diameters is considered, although three additional cases with other overburdens are employed to analyze its influence.

\subsection{Limit Analysis: methodology and results}

To validate the Limit Analysis mechanism that considers the influence of pore water pressure, and in particular to compare its results with the results of a numerical model, it would be enough to use the same pore water pressure distribution -using e.g., the pore water pressure coefficient $r_{u}$ defined by Bishop and Morgenstern (1960)- and to compare the results of both approaches. However, to be able to study accurately the effect of advance drainage on the tunnel face stability, the FLAC ${ }^{3 \mathrm{D}}$ numerical model described in Section 2.3 is used to enable us to work with more realistic pore pressure distributions.

Table 1

Test Cases considered for numerical validation of the Limit Analysis mechanism. (Diameter: $D=10 \mathrm{~m}$; strength properties: $c=0 \mathrm{kPa}$ and $\varphi=35^{\circ}$; saturated unit weight: $\gamma_{\text {sat }}=15.6 \mathrm{kN} / \mathrm{m}^{3}$ ).

\begin{tabular}{|c|c|c|c|c|c|c|c|c|c|}
\hline \multirow[t]{2}{*}{ Case } & \multirow[t]{2}{*}{$H_{w} / D$} & \multirow[t]{2}{*}{$C / D$} & \multirow[t]{2}{*}{ Position of drainage } & \multicolumn{2}{|c|}{ Collapse Pressure } & \multicolumn{2}{|c|}{ Reduction with respect to "No drainage" case } & \multicolumn{2}{|l|}{ Difference LA vs NS } \\
\hline & & & & $\sigma_{T(L A)}[\mathrm{kPa}]$ & $\sigma_{T(N S)}[\mathrm{kPa}]$ & $R_{(L A)}[\mathrm{kPa}]$ & $R_{(N S)}[\mathrm{kPa}]$ & $\left|\sigma_{T(L A)}-\sigma_{T(N S)}\right|[\mathrm{kPa}]$ & $\frac{\left|\sigma_{T(L A)}-\sigma_{T(N S)}\right|}{\sigma_{T(N S)}}[\%]$ \\
\hline 1 & 2 & 2 & Without & 87.4 & 83.1 & - & - & 4.3 & 5.1 \\
\hline 2 & 3 & 2 & Without & 118.4 & 112.6 & - & - & 5.8 & 5.2 \\
\hline 3 & 4 & 2 & Without & 151.2 & 142.7 & - & - & 8.5 & 5.8 \\
\hline 4 & 5 & 2 & Without & 184.1 & 173.0 & - & - & 11.1 & 6.4 \\
\hline 5 & 2 & 2 & Upper & 64.2 & 61.3 & 23.2 & 21.8 & 2.9 & 4.8 \\
\hline 6 & 3 & 2 & Upper & 83.6 & 80.1 & 34.8 & 32.5 & 3.5 & 4.3 \\
\hline 7 & 4 & 2 & Upper & 103.2 & 99.0 & 48 & 43.7 & 4.2 & 4.3 \\
\hline 8 & 5 & 2 & Upper & 123.1 & 119.5 & 61 & 53.5 & 3.6 & 3.0 \\
\hline 9 & 2 & 2 & Lower & 59.7 & 57.5 & 27.7 & 25.6 & 2.2 & 3.8 \\
\hline 10 & 3 & 2 & Lower & 80.8 & 77.6 & 37.6 & 35 & 3.2 & 4.0 \\
\hline 11 & 4 & 2 & Lower & 102.6 & 98.4 & 48.6 & 44.3 & 4.2 & 4.2 \\
\hline 12 & 5 & 2 & Lower & 124.6 & 119.4 & 59.5 & 53.6 & 5.2 & 4.4 \\
\hline 13 & 3 & 3 & Upper & 82.2 & 78.6 & - & - & 3.8 & 4.5 \\
\hline 14 & 4 & 4 & Upper & 103.3 & 99.7 & - & - & 3.6 & 3.6 \\
\hline 15 & 5 & 5 & Upper & 122.8 & 120.6 & - & - & 2.2 & 1.8 \\
\hline
\end{tabular}

Note. LA: Limit Analysis mechanism; NS: Numerical simulation with FLAC ${ }^{3 \mathrm{D}}$. 

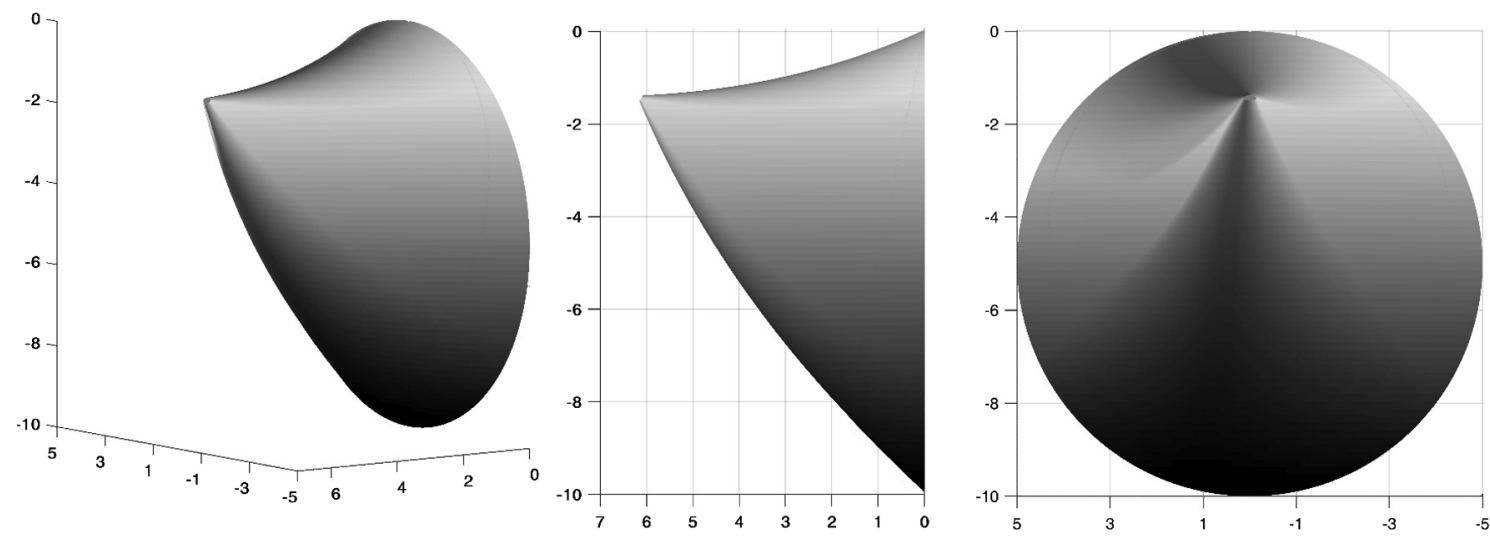

(a)
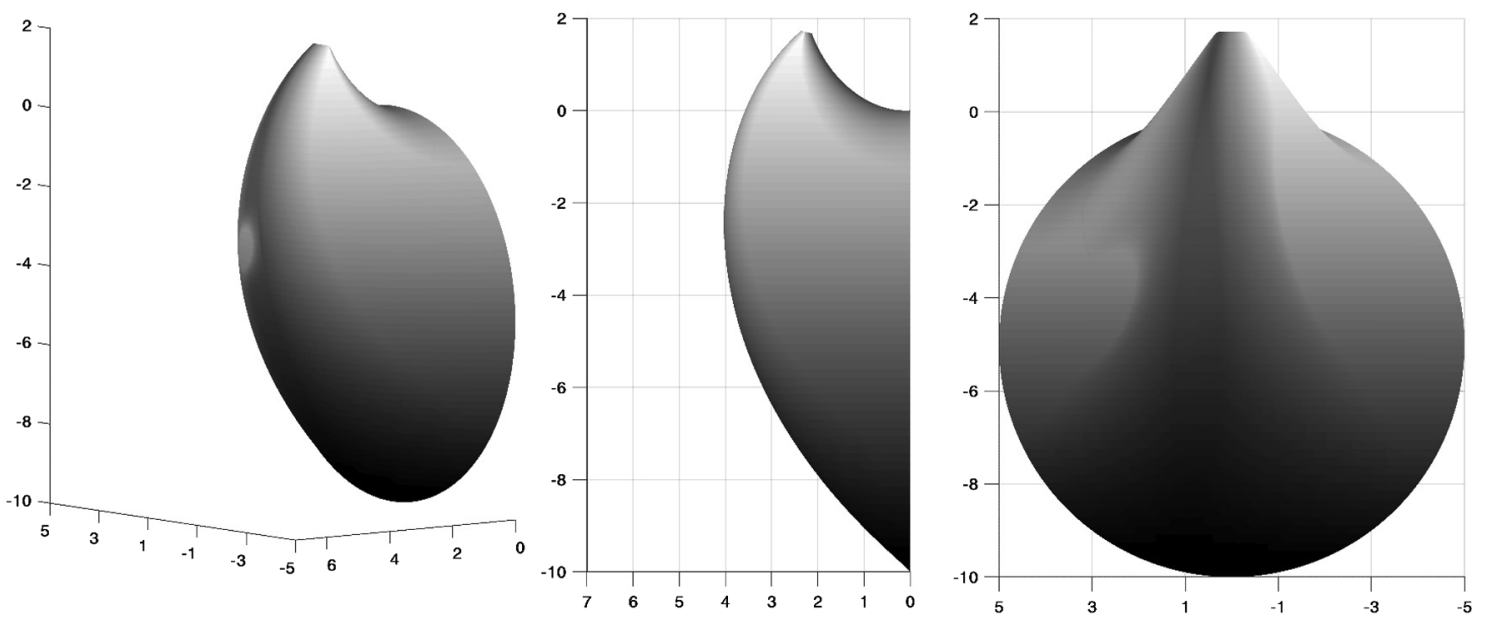

(b)
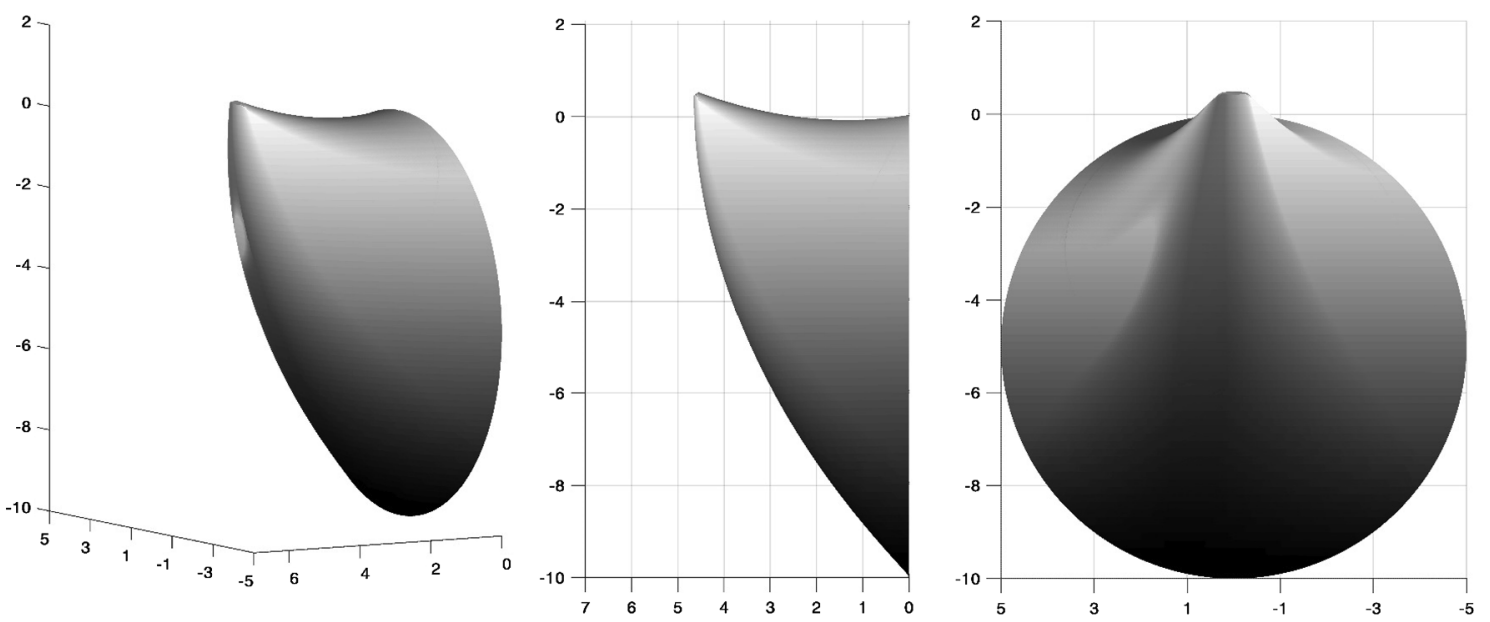

(c)

Fig. 7. Examples of the failure geometries obtained with the Limit Analysis mechanism: (a) Test Case 2 (without drainage); (b) Test Case 6 ("upper" drainage); (c) Test Case 10 ("lower" drainage). ( $D=10 \mathrm{~m} ; C=2 D ; H_{w}=3 D$ ).

To that end, pore water pressures are extracted from the numerical model using a FISH routine (the built-in programming language in FLAC $^{3 \mathrm{D}}$ ), and they are then transferred to the code of the Limit Analysis solution (implemented in MATLAB, The MathWorks, 2019). And, since the positions of nodes in the numerical model generally do not coincide with the positions of the centers of the triangular facets that define the collapse mechanism (i.e., where they are required to compute the support pressure in Eq. (6)), pore water pressures at the centers of facets are interpolated from the distributions computed with FLAC ${ }^{3 \mathrm{D}}$. Then, the critical collapse pressure is computed as explained in Section 2.2. Table 1 lists the critical pressures obtained with the Limit Analysis mechanism, and Fig. 7 shows three examples of the collapse geometries 
(a)

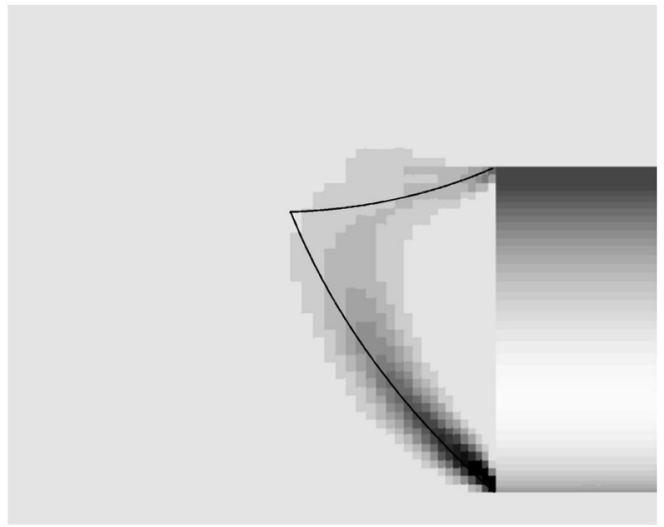

(b)

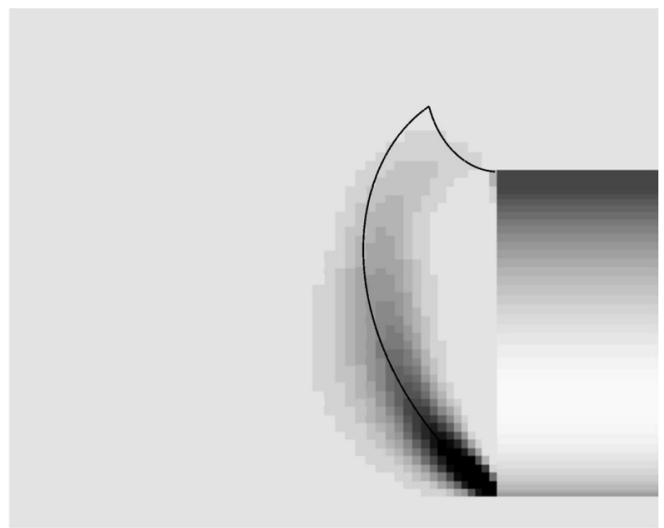

(c)

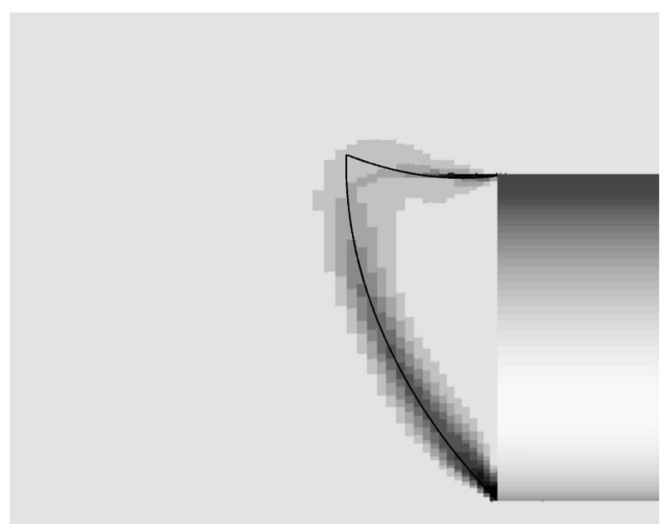

Fig. 8. Comparison of failure mechanisms computed with the Limit Analysis solution and with the numerical simulation for different drainage configurations: (a) without drainage (Test Case 2); (b) "upper" drainage (Test Case 6); (c) "lower" drainage (Test Case 10$).\left(D=10 \mathrm{~m} ; C=2 D ; H_{w}=3 D\right)$.

obtained with the analytical solution for the different drainage configurations (without drainage, and with "upper" and "lower" drainage).

\subsection{Numerical analysis: methodology and results}

The numerical model to compute the collapse pressure of the tunnel face considering the influence of water is identical to that presented in Section 2.3. The constitutive model for the ground is elastic-perfectly plastic, using the Mohr-Coulomb failure criterion as implemented in FLAC $^{3 \mathrm{D}}$, and with an associated flow rule so that it fulfills the requirements of Limit Analysis. The model is configured to "mechanical calculation" only, so that pore pressures do not change during the simulation. (Note, however, that they are employed to compute effective stresses and to detect failure; Itasca Consulting Group, 2009). As before, the pore pressure distribution is imported from a (flow only) numerical simulation. (In this way, we ensure that the distribution is the same for both calculations so that it does not affect the computed results).

The improved bisection method, proposed by Mollon et al. (2009), is adopted to compute the collapse pressure in the numerical model. According to Senent et al. (2013), we employ a value of 1EXP-07 as the convergence criterion for the unbalanced mechanical-force ratio and the collapse pressure is computed with a precision of $0.1 \mathrm{kPa}$. The obtained values are listed in Table 1 . The collapse geometry in the numerical model can be visualized using the distribution of shear strain rates. Figs. 8-10 show the failure mechanisms -as observed within the vertical plane of symmetry of the tunnel- computed with the numerical model for different drainage configurations (Fig. 8), water levels (Fig. 9) and overburdens (Fig. 10); collapse geometries from the Limit Analysis analytical solution are added in these figures for comparison (see Section 3.4). (The obtained geometries and the influence of the different variables will be discussed in Section 4.)

\subsection{Comparison}

Results in Table 1 show that collapse pressures computed with the analytical solution and the numerical model are very similar, with absolute differences that typically are in the range of $2-6 \mathrm{kPa}$, or with relative differences that are typically less than $6 \%$. Consequently, the proposed Limit Analysis mechanism can be employed to compute face collapse pressures considering the influence of advance drainage. Note also that the Limit Analysis results are higher than those computed with the numerical model. Since this is an upper bound solution in the framework of Limit Analysis, and given that the face pressure acts against the movement of the mechanism, the obtained values should be lower than the ones given by the numerical simulation. Several reasons can justify this incoherence, including the mesh size in the numerical model (e.g. Mollon et al., 2011b), the locations of the model boundaries, or the precision of the method employed to calculate the collapse pressure. Table 1 also shows that the differences between the numerical model and the analytical solution tend to increase as the water table raises; on the other hand, Test Cases with drainage show lower differences than those without drainage. That is, differences between the analytical solution and the numerical model increase as the pore water pressures ahead of the tunnel face increase. Therefore, caution should be exercised if the Limit Analysis mechanism is employed to study the face stability in tunnels under higher water pressures (i.e., with $H_{w}>5 D$, for a $D=10 \mathrm{~m}$ tunnel).

Finally, the shape of the failure mechanisms obtained with the Limit Analysis approach agrees satisfactorily with the numerical simulation results (Figs. 8-10). The agreement is excellent in the lower part of the mechanism and approximated in the upper part. (However, note that, as indicated by Mollon et al. (2011b), the lower part of the mechanism has the main contribution to the computed face collapse pressure for a constant applied pressure.) In the upper part of the mechanism the numerical model shows more rounded failure geometries, whereas the geometry of the analytical solution is sharper. This is more relevant in the case without drainage (Fig. 8(a)), in contrast with other cases for which the agreement is better. In conclusion, the analytical solution gives a good approximation of the collapse geometry in all cases and it can be employed to reasonably predict the shape of the failure surface.

\section{Effect of advance drainage on the stability of the tunnel face}

Results in Table 1 show that rising the water table increases the collapse pressure in all drainage configurations (Cases 1-4 without drainage; Cases 5-8 and Cases 9-12 with "upper" and "lower" drainage respectively). As noted by Zingg (2016), even a very simple drainage 
(a)

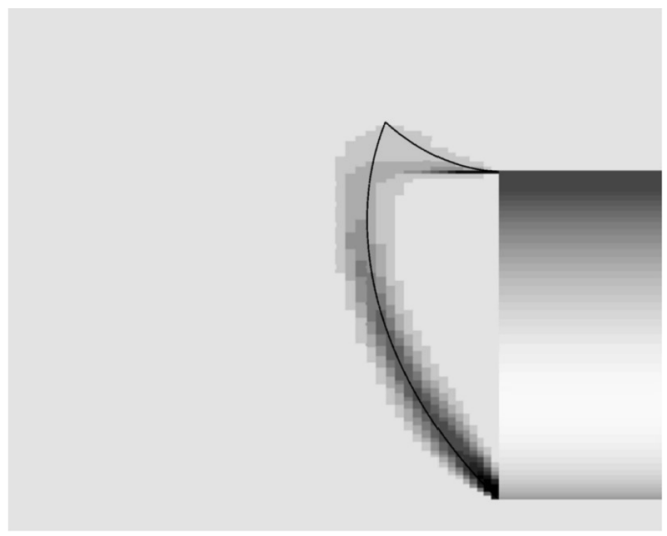

(c)

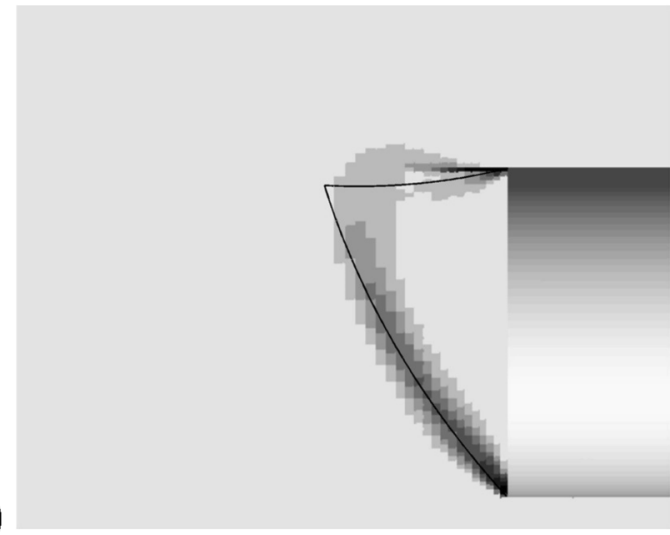

(b)

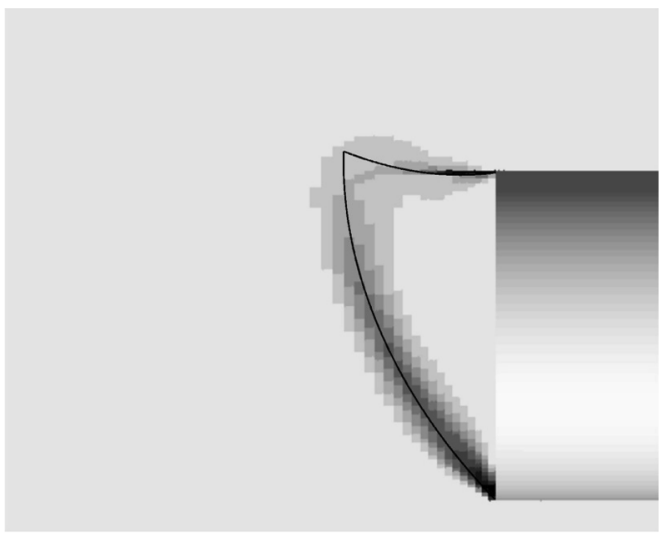

(d)

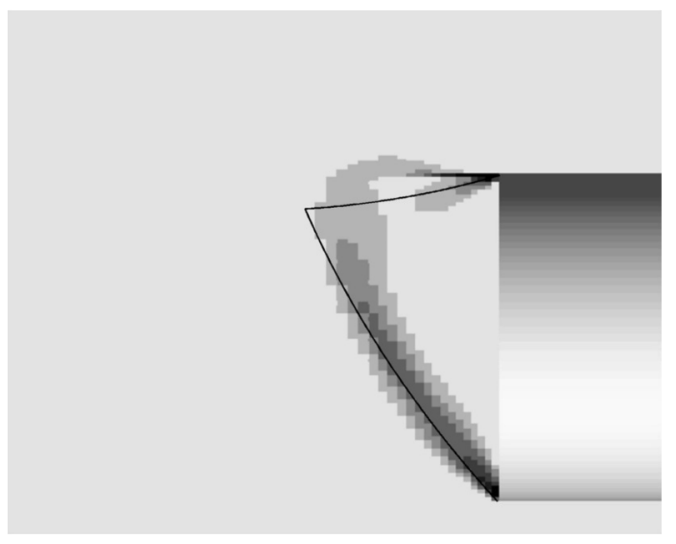

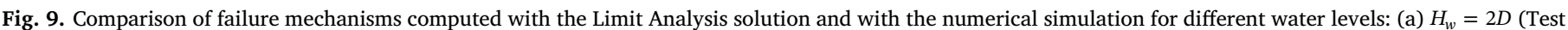
Case 9); (b) $H_{w}=3 D$ (Test Case 10); (c) $H_{w}=4 D$ (Test Case 11); (d) $H_{w}=5 D$ (Test Case 12). $(D=10 \mathrm{~m}$; $C=2 D$; "lower" drainage).

with only two boreholes significantly reduces the critical pressure (around $25-30 \%$ of its value) due to the reduction of the pore water pressure ahead of the tunnel face. Results also show that both drainage configurations ("upper" and "lower") produce similar reductions of the collapse pressure. Finally, the comparison of Test Cases 13-15 and Test Cases 6-8 suggests that the overburden does not significantly influence the value of the collapse pressure.

Figs. 7 and 8 illustrate that the shape of the critical failure mechanism is affected by the drainage configuration employed: in the case without drainage (Figs. 7(a) and 8(a)), the mechanism does not extend upwards and it evolves towards the region directly ahead of the tunnel face. With "upper" drainage (Figs. 7(b) and 8(b)), the mechanism develops vertically towards the region above the tunnel crown, hence developing a similar shape to that obtained in studies considering dry ground (e.g., Senent et al., 2013). Note also that, without drainage, the mechanism extends further ahead of the tunnel face than when "upper" drainage is employed (approximately $6 \mathrm{~m}$ vs $4 \mathrm{~m}$ in the Limit Analysis mechanism). This is probably because the mechanism tries to mobilize as much energy (from the external loads) as possible, so that it tends to develop towards the region with higher pore water pressures when there is no drainage; with drainage, however, the effect of water is less important, and the mechanism tries to optimize the relationship between its volume and its surface. Finally, with "lower" drainage (Figs. 7(c) and 8(c)), the reduction of pore pressures ahead of the upper part of the face is less significant (see Fig. 5(c)), so that the mechanism tries again to develop towards the region with higher pore pressures.

Fig. 9 suggests that the variation of the failure geometry discussed in the previous paragraph is more relevant as the water level increases, so that when the pore pressures ahead of the tunnel increase, the mechanism tends to become more horizontal, trying to develop itself deeper into the region ahead of the tunnel face. To better show these results, Fig. 11 plots a comparison between the three drainage configurations considered -without drainage, "upper" drainage and "lower" drainage- when $H_{w} / D=3$ (Fig. 11(a)) and $H_{w} / D=4$ (Fig. 11(b)), clearly illustrating that (i) the shape of the mechanism changes depending on the drainage configuration, and (ii) the "horizontalization effect" is more relevant for cases without drainage and with "lower" drainage, whereas it is almost irrelevant when the drainage is in the upper part of the tunnel face.

Finally, Fig. 10 shows two cases with the same water table and with "upper" drainage, but with different overburdens. As it can be seen, the collapse geometry is almost equal in both cases, hence suggesting that overburden does not affect much the geometry of the failure surface (and neither the collapse pressure, as shown in Table 1).

\section{Comparison with other solutions from the literature}

In this section, the proposed Limit Analysis mechanism is compared with a Limit Equilibrium solution from the literature (Anagnostou and Kovári, 1994, 1996), which was previously employed to study the effect of drainage on tunnel face stability (Zingg, 2016). Although Zingg studies the effect of different drainage designs (such as drainage boreholes in different numbers and layouts, or pilot tunnels), our comparison is limited to the two drainage layouts analyzed in this work. 
(a)

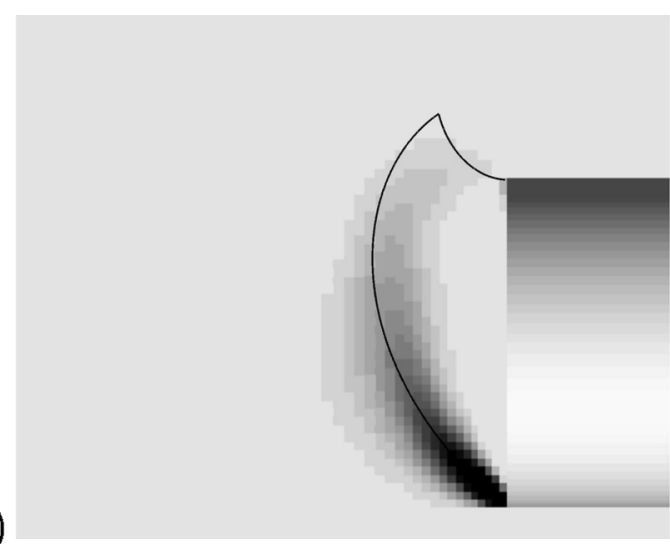

(b)

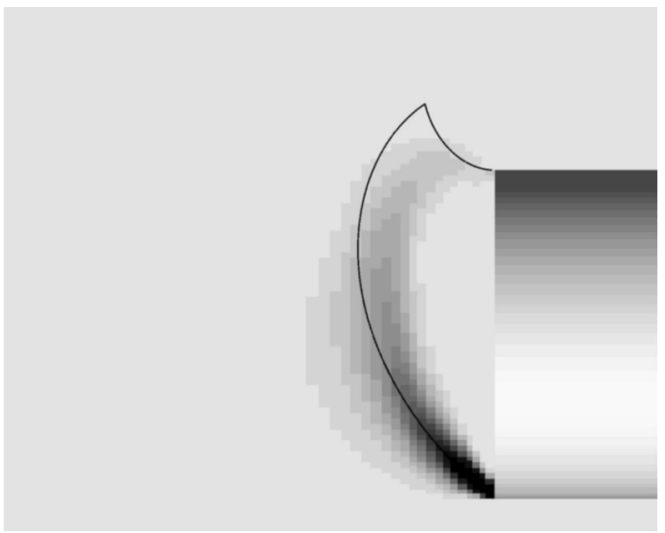

Fig. 10. Comparison of failure mechanisms computed with the Limit Analysis solution and with the numerical simulation for different overburdens: (a) $C=2 D$ (Test Case 6); (b) $C=3 D$ (Test Case 13). ( $D=10 \mathrm{~m} ; H_{w}=3 D$; "upper" drainage).

(a)

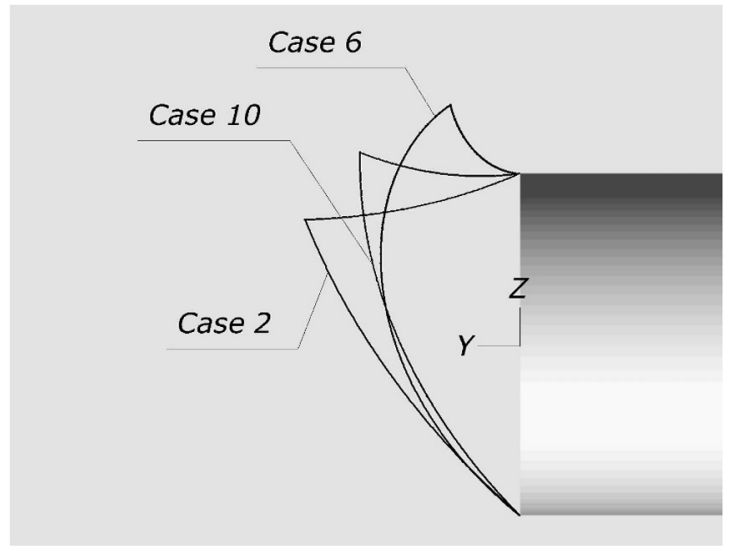

(b)

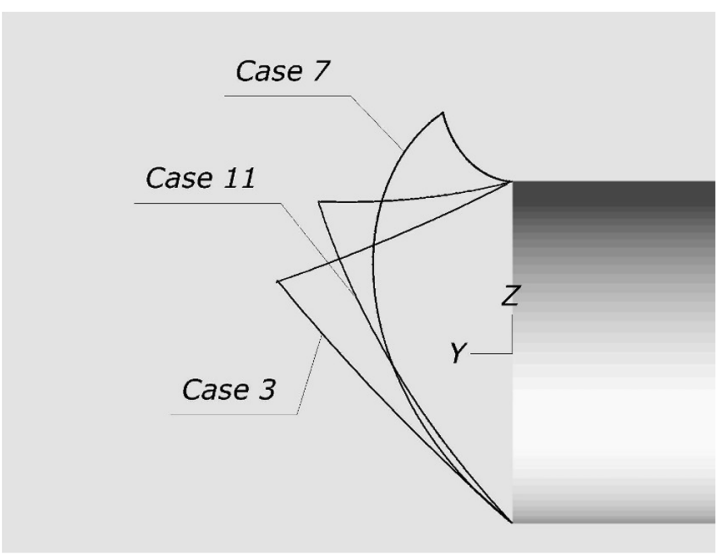

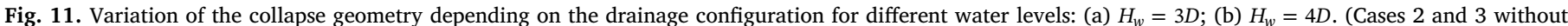
drainage; Cases 6 and 7 "upper" drainage; Cases 10 and 11 "lower" drainage). $(D=10 \mathrm{~m} ; C=2 D)$.

Consequently, a $10 \mathrm{~m}$ diameter tunnel excavated in a purely frictional material (with $\left.\varphi=35^{\circ}\right)$ and with different water table elevations $\left(H_{w} / D\right.$ from 2 to 5 ) is considered, with two drainage boreholes with $\mathrm{L}=30 \mathrm{~m}$ length located at the upper and lower part of the tunnel face (they correspond to the "upper" and "lower" drainage configurations presented in Fig. 1(b)). (A third case, i.e., a tunnel without drainage, is also considered for reference and comparison). In addition, note that, due to the limitation of the Limit Equilibrium mechanism to compute the collapse pressure when the submerged weight of the soil is lower than a threshold -in the case without advance drainage, for $\gamma^{\prime} \leq 7.9 \mathrm{kN} / \mathrm{m}^{3}$ - a saturated weight of $20 \mathrm{kN} / \mathrm{m}^{3}$ is employed for this comparison. Note also that Zingg (2016) studies subaqueous tunnels with $H_{w}>5 D$, whereas this work analyzes tunnels with lower $H_{w}$. Consequently, the Limit Equilibrium results presented herein are not directly taken from Zingg (2016); they are computed using our own MATLAB implementation of the formulation presented in that work.

Table 2 lists the Test Cases employed for comparison, and the collapse pressures obtained for each case with both analytical solutions

Table 2

Test Cases considered to compare the Limit Analysis mechanism with the Limit Equilibrium methodology presented by Zingg (2016). (Diameter: $D=10 \mathrm{~m}$; strength properties: $c=0 \mathrm{kPa}$ and $\varphi=35^{\circ}$; saturated unit weight: $\gamma_{\text {sat }}=20 \mathrm{kN} / \mathrm{m}^{3}$ ).

\begin{tabular}{|c|c|c|c|c|c|c|c|c|c|}
\hline \multirow[t]{2}{*}{ Case } & \multirow[t]{2}{*}{$H_{w} / D$} & \multirow[t]{2}{*}{$C / D$} & \multirow[t]{2}{*}{ Position of drainage } & \multicolumn{2}{|c|}{ Limit Analysis } & \multicolumn{2}{|c|}{ Limit Equilibrium } & \multicolumn{2}{|c|}{ Numerical Simulation with FLAC ${ }^{3 D}$} \\
\hline & & & & $\sigma_{T(L A)}[\mathrm{kPa}]$ & $w\left[^{\circ}\right]$ & $\sigma_{T(L E)}[\mathrm{kPa}]$ & $w\left[^{\circ}\right]$ & $\sigma_{T(N S)}[\mathrm{kPa}]$ & $w\left[^{\circ}\right]$ \\
\hline 1 & 2 & 2 & Without & 90.9 & 50 & 135.3 & 64 & 83.5 & 46 \\
\hline 2 & 3 & 2 & Without & 121.3 & 51 & 200.0 & 68 & 112.8 & 46 \\
\hline 3 & 4 & 2 & Without & 153.1 & 50 & 264.4 & 70 & 142.6 & 45 \\
\hline 4 & 5 & 2 & Without & 185.7 & 50 & 330.3 & 72 & 173.1 & 47 \\
\hline 5 & 2 & 2 & Upper & 67.3 & 51 & 80.4 & 42 & 61.6 & 47 \\
\hline 6 & 3 & 2 & Upper & 87.3 & 49 & 111.4 & 44 & 80.2 & 48 \\
\hline 7 & 4 & 2 & Upper & 103.3 & 51 & 142.9 & 44 & 99.7 & 52 \\
\hline 8 & 5 & 2 & Upper & 126.7 & 51 & 174.5 & 44 & 119.5 & 52 \\
\hline 9 & 2 & 2 & Lower & 63.8 & 44 & 75.6 & 38 & 57.8 & 43 \\
\hline 10 & 3 & 2 & Lower & 84.6 & 44 & 109.3 & 40 & 78.1 & 40 \\
\hline 11 & 4 & 2 & Lower & 106.2 & 43 & 143.6 & 40 & 98.8 & 41 \\
\hline 12 & 5 & 2 & Lower & 127.9 & 44 & 178.1 & 42 & 119.4 & 42 \\
\hline
\end{tabular}




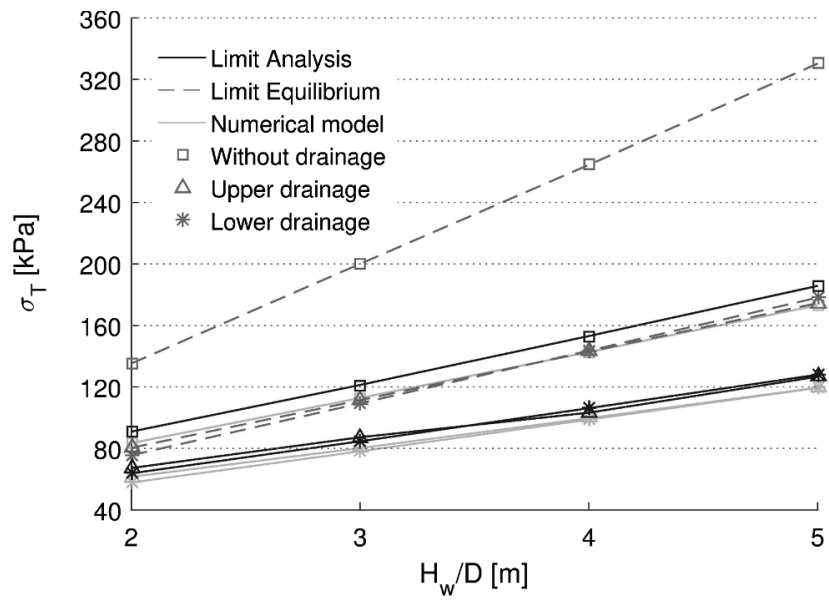

Fig. 12. Collapse pressures computed with the Limit Analysis mechanism, with the Limit Equilibrium methodology presented by Zingg (2016), and with a numerical simulation in FLAC ${ }^{3 \mathrm{D}}$, for different drainage configurations. (See Table 2.)

(Limit Analysis and Limit Equilibrium); results computed with a FLAC ${ }^{3 \mathrm{D}}$ numerical model are reported as well. These values are plotted in Fig. 12. As previously, collapse pressures computed with the Limit Analysis mechanism are similar to results from the numerical model. Results from the Limit Equilibrium mechanism are, in all cases, higher than those computed with Limit Analysis and with FLAC ${ }^{3 \mathrm{D}}$ (with relative differences generally of around $15-29 \%$, and reaching $44 \%$ in the case without drainage), and with absolute differences that increase with $H_{w} / D$; this, however, suggests that the Limit Equilibrium approach provides a safe estimation. The reason why the results of the Limit Analysis mechanism are closer to the results of the numerical model could be due to the fact that the same hypothesis (mainly, the associated flow rule) are considered in both approaches.

In any case, all the methodologies demonstrate that: (i) collapse pressures increase dramatically with the raise of the water level (i.e., with $H_{w} / D$ ); (ii) advance drainage greatly reduces the collapse pressure, particularly for higher water tables; and (iii) the location of the drainage boreholes does not affect the value of the collapse pressure

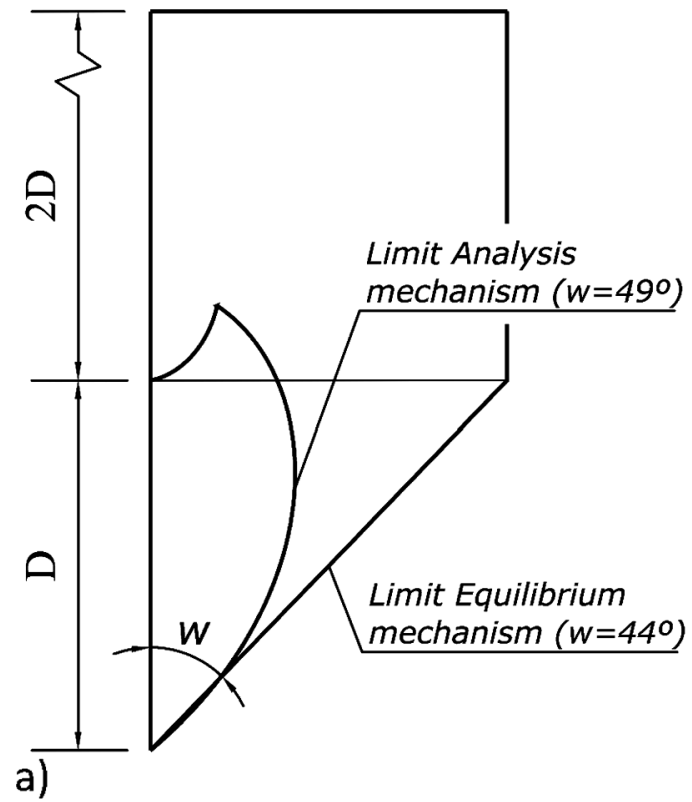

significantly, although it has some influence on the shape of the critical failure geometry. In addition, results show that "lower" drainage is more effective when the water table is low (between 3 and 4 diameters depending on the method employed, for the values considered in this study); whereas, "upper" drainage is more effective when the water table is higher than $4 D$. These results are coherent with previous research; e.g., Hong et al. (2007) recommended "upper" drainage in the case of a tunnel with $H_{w} / D \approx 13.8$.

Finally, the failure geometry of the Limit Equilibrium solution -formed by a wedge and an upper prism- is compared to the rotational failure mechanism obtained with Limit Analysis. Fig. 13 shows two examples, with $C / D=2$ and $H_{w} / D=3$ and with "upper" and "lower" drainage (Fig. 13(a) and (b) respectively). Note that both analytical solutions predict very similar initial slopes (or critical angle, $w$ ) of the mechanism in its lower part, and that differences in the upper part are substantial. Table 2 summarizes the critical angles computed with the Limit Equilibrium solution for all cases considered, and the angles extracted from the Limit Analysis mechanism and from the numerical model. All approaches produce similar values, except for situations without drainage, in which Limit Analysis and the numerical model produce more similar results. For the cases considered, the critical angle for cases with "upper" drainage is higher than for "lower" drainage. This result disagrees with Zingg (2016), who obtained that "lower" drainage produced higher angles; the discrepancy is probably due to the different $H_{w} / D$ ratios considered $\left(H_{w} / D \leq 5\right.$ are employed herein, whereas Zingg (2016) employed $H_{w} / D>5$ ).

\section{Conclusions}

The effect of advance drainage boreholes is incorporated into the Limit Analysis rotational collapse mechanism developed by Mollon et al. (2011a). Our aim is to study the face stability of a circular tunnel, with $D=10 \mathrm{~m}$, constructed under the water table, with particular attention on their failure modes and on their collapse pressures, for different drainage configurations (without drainage, and with drainage in the upper and in the lower part of the tunnel face). The pore water pressure on the external surface of the collapse mechanism is interpolated from pore water pressure distributions computed with FLAC ${ }^{3 \mathrm{D}}$. Critical pressures and failures geometries calculated with the analytical solution reasonably reproduce the results from the numerical

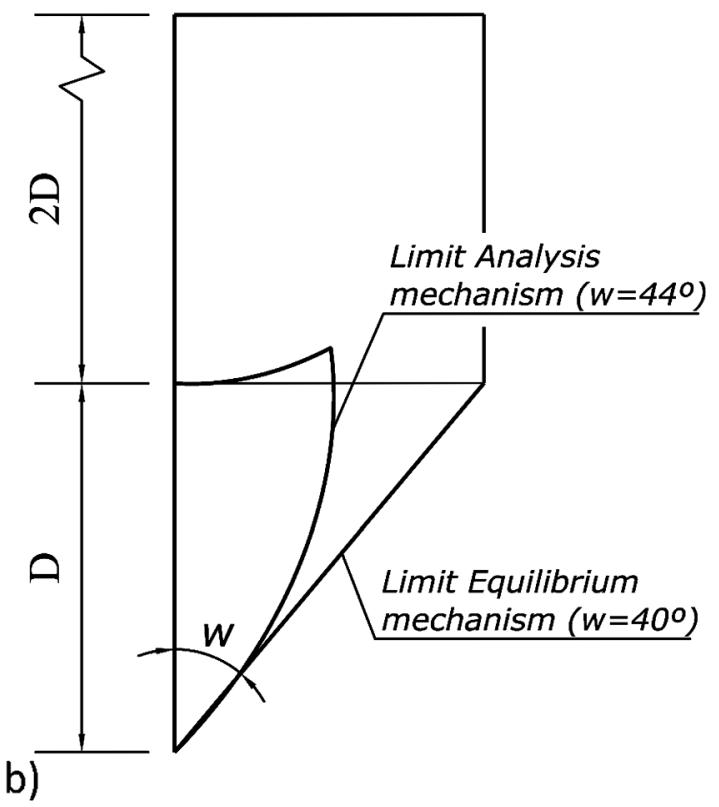

Fig. 13. Comparison of the failure geometries obtained with the Limit Analysis mechanism and with the Limit Equilibrium methodology presented by Zingg (2016): (a) "upper" drainage (Test Case 6 in Table 2); (b) "lower" drainage (Test Case 10 in Table 2). $\left(D=10 \mathrm{~m} ; C=2 D ; H_{w}=3 D\right.$ ). 
simulations, especially when the height of the water table above the tunnel crown is lower than 5 diameters.

Results show an expected increase of the critical pressure when the water level raises, and highlight the importance of drainage measures on the stability of the face. The location of the drainage boreholes is not so relevant, for the studied cases, although a "lower" drainage is more effective when the water table is lower $\left(H_{w} / D<3\right)$, whereas an "upper" drainage is recommended when the water table is higher $\left(H_{w} / D>4\right)$. Results also show that the failure geometry is clearly influenced by the drainage configuration, $\mathrm{s} o$ that $\mathrm{f}$ or $\mathrm{c}$ ases $\mathrm{w}$ ithout $\mathrm{d}$ rainage a nd with "lower" drainage the mechanism develops more horizontally into the ground ahead of the tunnel face, whereas with "upper" drainage the mechanism develops more vertically, towards the region above the tunnel crown. The shape of the critical collapse mechanism, particularly the tendency to develop more horizontally (or not), is also heavily affected by the position of the water table.

Comparing the proposed methodology with the classical Limit Equilibrium mechanism of Anagnostou and Kovári (1994, 1996) (Zingg, 2016), formed by a wedge and an upper prism, the Limit Analysis approach gives lower values of the collapse pressure (with differences up to $30-45 \%$ mainly depending on the water level and on the drainage configuration), that generally agree better with the numerical simulation results. Furthermore, similar values of the initial slope of the mechanism in its lower part are obtained with both methodologies.

\section{Acknowledgements}

This research was funded, in part, by the Spanish Ministry of Economy, Industry and Competitiveness under Grant BIA2015-69152-R and CIEN Program (TUÑEL Project). The first author holds a PhD Scholarship provided by the China Scholarship Council. The support of both institutions is gratefully acknowledged.

\section{References}

Anagnostou, G., 2014. Some critical aspects of subaqueous tunnelling. Muir Wood Lecture 2014. ITA-AITES World Tunnel Congress (WTC2014).

Anagnostou, G., Kovári, K., 1994. The face stability of slurry-shield-driven tunnels. Tunn. Undergr. Space Technol. 9 (2), 165-174. https://doi.org/10.1016/0886-7798(94) 90028-0.

Anagnostou, G., Kovári, K., 1996. Face stability conditions with earth-pressure-balanced shields. Tunn. Undergr. Space Technol. 11 (2), 165-173. https://doi.org/10.1016/ 0886-7798(96)00017-X.

Bishop, A.W., Morgenstern, N.R., 1960. Stability coefficients for earth slopes.
Géotechnique 10 (4), 129-150. https://doi.org/10.7939/R35M62D9F.

Hong, E.S., Shin, H.S., Kim, H.M., Park, C., Park, E.S., 2007. Numerical study on horizontal pre-drainage system using horizontal directional drilling in subsea tunnelling Chin. J. Rock Mech. Eng. 26 (S2), 3697-3703.

Itasca Consulting Group, 2009. FLAC3D 4.0 Manual. Minneapolis.

Leca, E., Dormieux, L., 1990. Upper and lower bound solutions for the face stability of shallow circular tunnels in frictional material. Geotechnique 40 (4), 581-606. https://doi.org/10.1680/geot.1990.40.4.581.

Lee, I.M., Nam, S.W., 2001. The study of seepage forces acting on the tunnel lining and tunnel face in shallow tunnels. Tunn. Undergr. Space Technol. 16 (1), 31-40. https:// doi.org/10.1016/S0886-7798(01), 00028-1.

Lee, I.M., Nam, S.W., Ahn, J.H., 2003. Effect of seepage forces on tunnel face stability. Can. Geotech. J. 40 (2), 342-350. https://doi.org/10.1139/t02-120.

Li, C., Miao, L., Lv, W., 2011. Numerical analysis of face stability during shield-driven tunneling under groundwater table. In: Reston, VA: ASCE Copyright Proceedings of the Geo-Frontiers 2011 Conference, March 13-16, 2011, Dallas, Texas|d 20110000. American Society of Civil Engineers. https://doi.org/10.1061/41165(397)388.

Lü, X., Zhou, Y., Huang, M., Zeng, S., 2018. Experimental study of the face stability of shield tunnel in sands under seepage condition. Tunn. Undergr. Space Technol. 74, 195-205. https://doi.org/10.1016/j.tust.2018.01.015.

Mair, R.J., 2008. Tunnelling and geotechnics: new horizons. Géotechnique 58 (9), 695-736. https://doi.org/10.1680/geot.2008.58.9.695.

Mollon, G., Dias, D., Soubra, A.H., 2009. Probabilistic analysis of circular tunnels in homogeneous soil using response surface methodology. J. Geotech. Geoenviron. Eng. 135 (9), 1314-1325. https://doi.org/10.1061/(ASCE)GT.1943-5606.0000060.

Mollon, G., Dias, D., Soubra, A.H., 2011a. Rotational failure mechanisms for the face stability analysis of tunnels driven by a pressurized shield. Int. J. Numer. Anal. Meth. Geomech. 35 (12), 1363-1388. https://doi.org/10.1002/nag.962.

Mollon, G., Phoon, K.K., Dias, D., Soubra, A.H., 2011b. Validation of a new 2D failure mechanism for the stability analysis of a pressurized tunnel face in a spatially varying sand. J. Eng. Mech. 137, 8-21. https://doi.org/10.1061/(ASCE)EM.1943-7889. 0000196.

Pan, Q., Dias, D., 2016. The effect of pore water pressure on tunnel face stability. Int. J. Numer. Anal. Meth. Geomech. 40 (15), 2123-2136. https://doi.org/10.1002/nag. 2528.

Pan, Q., Dias, D., 2018. Three dimensional face stability of a tunnel in weak rock masses subjected to seepage forces. Tunn. Undergr. Space Technol. 71, 555-566. https://doi. org/10.1016/j.tust.2017.11.003.

Senent, S., Mollon, G., Jimenez, R., 2013. Tunnel face stability in heavily fractured rock masses that follow the Hoek-Brown failure criterion. Int. J. Rock Mech. Min. Sci. 60, 440-451. https://doi.org/10.1016/j.ijrmms.2013.01.004.

The MathWorks, Inc., 2019. MATLAB (MATrix LABoratory), Version 9.6 (R2019a).

Viratjandr, C., Michalowski, R.L., 2006. Limit analysis of submerged slopes subjected to water drawdown. Can. Geotech. J. 43 (8), 802-814. https://doi.org/10.1139/t06042.

Zingg, S., 2016. Static effects and aspects of feasibility and design of drainages in tunnelling. PhD Thesis. ETH Zurich. (Dissertation Nr. 23729). https://doi.org/10.3929/ ethz-a-010780201.

Zingg, S., Anagnostou, G., 2016. An investigation into efficient drainage layouts for the stabilization of tunnel faces in homogeneous ground. Tunn. Undergr. Space Technol. 58, 49-73. https://doi.org/10.1016/j.tust.2016.04.004.

Zingg, S., Anagnostou, G., 2018. Tunnel face stability and the effectiveness of advance drainage measures in water-bearing ground of non-uniform permeability. Rock Mech. Rock Eng. 51 (1), 187-202. https://doi.org/10.1007/s00603-017-1312-1. 